\title{
NanoCarb spaceborne miniaturized GHG sensor: first experimental results
}

Silvère Gousset, Juana M. Rodrigo, Etienne Le Coarer, Hélène Ehrhardt, Eric Stadler, et al.

Silvère Gousset, Juana M. Rodrigo, Etienne Le Coarer, Hélène Ehrhardt, Eric Stadler, Zoltán Hubert, Yves Magnard, Laurence Croizé, Yann Ferrec, Florence de la Barrière, Roland Domel, Christophe Coudrain, Remi Gouyon, Mathieu Chambon, Philippe Perrault, Jumana Boussey, Cécile Gourgon, Marie Panabière, Nadine Gerges, "NanoCarb spaceborne miniaturized GHG sensor: first experimental results," Proc. SPIE 11852, International Conference on Space Optics — ICSO 2020, 118522L (11 June 2021); doi: $10.1117 / 12.2599429$

SPIE Event: International Conference on Space Optics - ICSO 2021, 2021, Online Only 


\section{International Conference on Space Optics-ICSO 2020}

Virtual Conference

30 March-2 April 2021

Edited by Bruno Cugny, Zoran Sodnik, and Nikos Karafolas
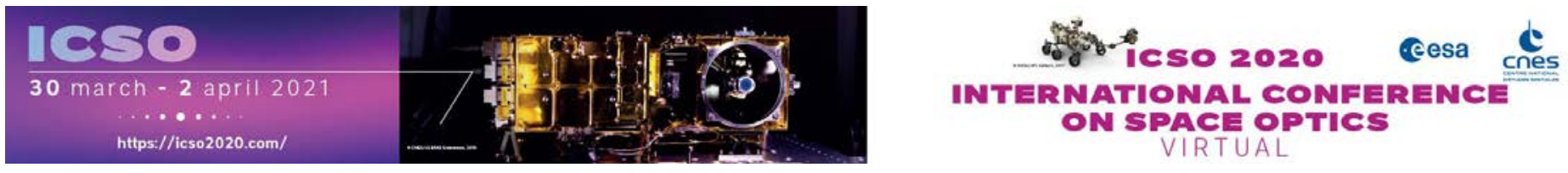

\section{NanoCarb spaceborne miniaturized GHG sensor: first experimental results}

\section{Cesa issopereatings denes}




\title{
NanoCarb airborne miniaturized GHG sensor: first experimental results
}

\author{
Silvère Gousset*a , Juana M. Rodrigo ${ }^{\mathrm{a}}$, Etienne Le Coarer ${ }^{\mathrm{a}}$, Hélène Ehrhardt ${ }^{\mathrm{a}}$, Eric Stadler ${ }^{\mathrm{a}}$, Zoltan \\ Hubert $^{\mathrm{a}}$, Yves Magnard ${ }^{\mathrm{a}}$, Laurence Croizéb ${ }^{\mathrm{b}}$ Yann Ferrec ${ }^{\mathrm{b}}$, Florence de la Barrière $^{\mathrm{b}}$, Roland Domel $^{\mathrm{b}}$, \\ Christophe Coudrain ${ }^{\mathrm{b}}$, Rémi Gouyon ${ }^{\mathrm{b}}$, Mathieu Chambon ${ }^{\mathrm{b}}$, Philippe Perrault ${ }^{\mathrm{b}}$, Jumana Boussey ${ }^{\mathrm{c}}$, \\ Cécile Gourgon $^{\mathrm{c}}$, Marie Panabière ${ }^{\mathrm{c}}$, Nadine Gerges ${ }^{\mathrm{c}}$ \\ a IPAG/UGA-CNRS, Université Grenoble-Alpes, 38058 Grenoble \\ b ONERA/DOTA, BP 80100, chemin de la Hunière, FR-91123 Palaiseau \\ c LTM/UGA-CNRS CEA-leti, Grenoble, France
}

\begin{abstract}
The Space CARBon Observatory (SCARBO) European program aims at assessing the monitoring of anthropogenic emissions of Green House Gas (GHG) with the uncovered goal of a sub-daily revisit of the Earth at an affordable cost. One of the main project scopes is the feasibility study of a hybrid constellation including both high accuracy reference missions (Copernicus CO2M or CNES MicroCarb mission) and 24 small-satellites onboarding innovative miniaturized payloads. The key GHG-sensor of the smallsat constellation is the NanoCarb concept, an unprecedently kilogram-class Fourier Transform imaging spectrometer. We are reporting here some preliminary experimental results from a demonstration airborne campaign. A low cost, 2-bands prototype designed for $\mathrm{CO}_{2}$ and $\mathrm{CH}_{4}$ measurement has been developed then integrated over a Falcon-20 from SAFIRE, jointly to SPEX aerosol sensor from SRON. During October 2020, we flew over Spain, Italy, and towards Poland from Francazal airport in Toulouse, France. Even if we did not have the opportunity to flight over a powerplant, a lot of data has been acquired and are being processed. After presented the instrument, mission and data products, we assess the data quality and the reliability of the model. We derive finally an expected sensitivity over $\mathrm{CO}_{2}$ and $\mathrm{CH}_{4}$ columns according to the background respectively about $1.5-2.5 \%$ and $5 \%$. We finally demonstrate the operability of this first TRL5 prototype of NanoCarb.
\end{abstract}

Keywords: Hyperspectral Sensor, Fourier Spectrometry, Atmospheric Remote Sensing, Green House Gas Monitoring, Airborne Demonstration

\section{INTRODUCTION}

\subsection{SCARBO project}

Anthropic activity impact on climate change is a scientific and politic key challenge [1]. It is supported by the universal climate agreement (Paris, 2015). The methodology used to estimate greenhouse gas emissions is generally based on "bottom-up" methodology, i.e. based on activity statistics and emission factors specific to each source. However, these estimates may be subject to large uncertainties due to poor estimation of emission factors and the existence of unrecognized sources. As a complement to these inventories, an assessment of emissions at global, national and regional scales can be carried out based on the evaluation of atmospheric measurements and models. This is known as a "topdown" approach. This approach allows linking measured atmospheric concentrations to greenhouse gas fluxes using a transport and chemistry model. It can be used to validate the bottom-up approach. To answer to this problematic, and complementary to current and planned exploratory missions, a constellation allowing to increase the spatial and temporal resolution (sub daily global coverage with a small footprint -1 km-, imaging capabilities, and high $\mathrm{CO}_{2}-1$ ppm- and $\mathrm{CH}_{4}$ $-10 \mathrm{ppb}$ - concentration) is required.

The H2020 SCARBO project (Space CARBon Observatory) aims at solving a key challenge of anthropogenic greenhouse gases (GHGs) monitoring from space: improving the temporal revisit over the various sites of interest while meeting the accuracy and spatial resolution requirements (as per the EU guidelines on anthropogenic GHGs monitoring). 
To do that a novel miniaturized static spectrometer concept called NanoCarb is currently being developed to be included on a constellation of small satellites and coupled with aerosol sensors and high-end reference instruments.

\subsection{NanoCarb}

NanoCarb is an imaging interferometer dedicated to the measurement of $\mathrm{CO}_{2}$ concentration in the atmosphere. It is based on the ImSPOC concept (patented by ONERA and IPAG [2]). This concept combines a multipath imager (lens array in front of single 2D detector) and an array of static Fabry-Perot filters (FP) used in a multiplex way, that is with a spectral coverage much wider than the free spectral range of the cavity. Thus, each Fabry-Perot filter is characterized by an optical path difference (the period of the transmitted spectrum) and not by a single wavelength. The lens array forms a collection of thumbnail images of the scene at the focal plane, and each step of the interferometer is placed in front of a lens from the lens array.

The specificity of NanoCarb [3] [4] [5] is to measure only few optical path differences (as many as Fabry-Perot filters), that is only a partial interferogram. This specificity leads to a paradigm shift, since it is impossible to retrieve the spectrum from a partial interferogram. Therefore, the estimation of the $\mathrm{CO}_{2}\left(\right.$ and $\left.\mathrm{CH}_{4}\right)$ column concentration has to be done directly from these partial interferograms.

\subsection{SCARBO campaign aims}

One of the aims of the SCARBO project was to bring NanoCarb sensor from a technology concept, TRL2, to a validated technology in relevant environment, TRL5. To reach this goal, two prototypes have been developed and operated during an airborne campaign, from a Falcon 20 from Safire ${ }^{1}$. Besides NanoCarb, this campaign also involved an aerosoldedicated instrument, SpexAirborne (Spectro-polarimeter for Planetary Exploration [6]), to experimentally demonstrate the possibility to reduce bias on $\mathrm{CO}_{2}$ by simultaneously retrieving $\mathrm{CO}_{2}$ and aerosols products. $\mathrm{A} \mathrm{CO}_{2} / \mathrm{CH}_{4}$ reference sensor, Mamap [7], was also initially expected, but, due to travel restrictions caused by the pandemic situation, Mamap could not take part to this campaign. These restrictions also made that the campaign, which was initially scheduled in May 2020, eventually took place in October 2020.

For NanoCarb, the main objectives of this campaign were (i) to operate the instruments in real condition, (ii) to process data and to evaluate their performances in real environment conditions and (iii) to demonstrate the capability to detect an anthropic emission plume by flying above a thermal power plant. Unfortunately, due to meteorological condition, this last aim has not been demonstrated, and should be the purpose of a future airborne campaign. The three scientific flights of this campaign were indeed on aerosol scenarios. Nevertheless, the data acquired by NanoCarb during this campaign are very rich in information concerning instrumental performances.

The two NanoCarb prototypes have been designed to detect and quantify the atmospheric carbon dioxide $\left(\mathrm{CO}_{2}\right)$ and methane $\left(\mathrm{CH}_{4}\right)$. Within the framework of the space mission definition [8], when very high detection performances are required, the NanoCarb instrument is based on the state-of-the-art MCT SWIR FPA $1 \mathrm{k} \times 1 \mathrm{k}$ NGP from Lynred [9]. However, within the framework of this airborne campaign, an in order to respect budget and delay imposed by the project, the two spectral imagers are based on a lower performance detector, the Snake detector from Lynred (InGaAs, 640x512 pixels, sensitivity between 0.9 and $1.7 \mu \mathrm{m}$ ). Our purpose is thus to experimentally validate our performance model with these prototypes and next to extrapolate performances to a NGP-based detection system.

The NanoCarb cameras are described in Section 2, see also [10] for more details about their laboratory characterization. An overview of the SCARBO airborne campaign is given in Section 3. Extraction of the interferograms from the raw data is the topic of Section 4, and Section 5 gives a few considerations about the performance estimation.

The main purpose of those three flights was to validate another instrumental concept dedicated to aerosol measurement known as SpexAirborne (Spectro-polarimeter for Planetary Exploration) and to experimentally demonstrate the possibility to reduce bias on $\mathrm{CO}_{2}$ by simultaneously retrieve $\mathrm{CO}_{2}$ and aerosols product. But data are also very rich in information concerning instrumental performances, and preliminary results will be presented in this article.

${ }^{1}$ www.safire.fr 


\section{NANOCARB AIRBORNE INSTRUMENT AND INTEGRATION}

\subsection{NanoCarb cameras}

As stated above, for this airborne campaign, two NanoCarb instruments have been developed: one dedicated $\mathrm{CO}_{2}$ and one dedicated to $\mathrm{CH}_{4}$. These two cameras have a very similar design, actually they only differ on the interferometric plate and on the spectral band. Apart from this, both cameras are based on a Snake InGaAs FPA from Lynred ${ }^{2}$ and an electronics provided by Noxant ${ }^{3}$. This FPA has $640 \times 512$ pixels of $15 \mu \mathrm{m}$ pitch. The microlens array as $8 \times 10$ microlenses, with a pitch of $960 \mu \mathrm{m}$, so that we have 80 thumbnails of 64x64 pixels imaged on the FPA. The focal length of these microlenses is $4.5 \mathrm{~mm}$, and a diaphragm array is set just in front of them to have individual square pupils; the side of these diaphragms is $600 \mu \mathrm{m}$, so that the radiometrically equivalent f-number of a microlens is about 6.6. The magnification of the front afocal lens is 0.67 : thus, the focal length of the whole optics is $3 \mathrm{~mm}$, leading to an iFOV of $5 \mathrm{mrad}\left(50 \mathrm{~m}\right.$ at $10000 \mathrm{~m}$ height). The FOV should be $\pm 9.2^{\circ}$, however due to edge effects, the useful FOV is limited to $\pm 6.6^{\circ}(50 \times 50$ pixels $)$.

The FPA temperature is regulated thanks to a Peltier module. A second Peltier module regulates the temperature of the interferometric plate.

The difference between the two NanoCarb cameras is limited to the spectral band and to the interferometric plate, to be adapted to the specific spectral signature of $\mathrm{CO}_{2}$ and $\mathrm{CH}_{4}$. Consequently, the spectral band for the $\mathrm{CO}_{2}$ camera is centred at $6215 \mathrm{~cm}^{-1}(1609 \mathrm{~nm})$ with a FWHM of $25 \mathrm{~cm}^{-1}(6 \mathrm{~nm})$, while for the $\mathrm{CH}_{4}$ the central wavenumber is $6083 \mathrm{~cm}^{-1}$ $(1644 \mathrm{~nm})$ with a FWHM of $66 \mathrm{~cm}^{-1}(18 \mathrm{~nm})$. These bands are defined on axis: the spectral band shifts towards the lower wavenumbers when the incidence angle increases. On Figure 1, we have plotted the spectral signature of $\mathrm{CO}_{2}$ and $\mathrm{CH}_{4}$, with the on-axis and off-axis $\left(10^{\circ}\right)$ measured transmissions of the filter.
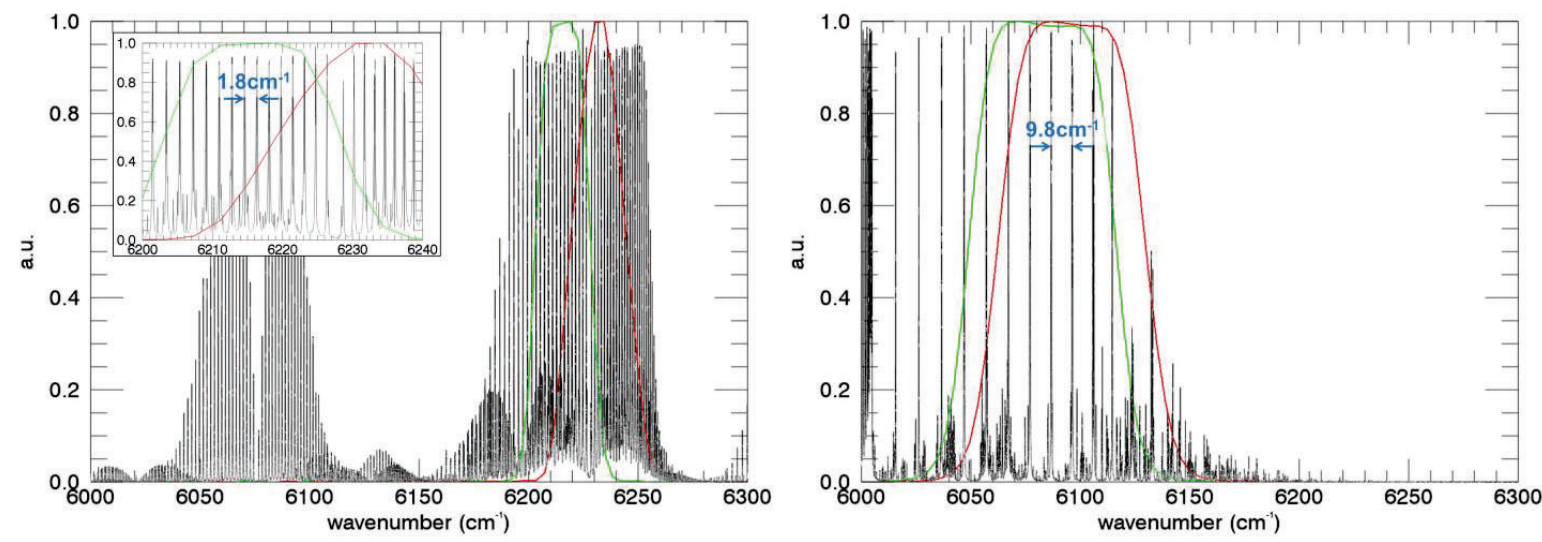

Figure 1. Spectral signature (jacobian spectrum) of $\mathrm{CO} 2$ (top) and $\mathrm{of}^{\mathrm{CH}_{4}}$ (bottom). The transmission of the NanoCarb bandpass filter is plotted in green for normal incidence, and in red for an incidence of $7^{\circ}$.

For both cameras, the interferometric plate is in Silicon, however the thickness is adapted to the specific gas. For $\mathrm{CO}_{2}$, the plate maximal thickness is $791 \mu \mathrm{m}$ : taking into account a group refractive index of Silicon equal to 3.59 [11], it means on OPD of $5.68 \mathrm{~mm}$ or a spectral period of $1,76 \mathrm{~cm}^{-1}$. The first 60 thicknesses of the steps on the plate etched by LTM are divided in three groups, henceforth labelled as $\mathrm{CO}_{2}-1, \mathrm{CO}_{2}-2$ and $\mathrm{CO}_{2}-3$, with respective thickness about $790 \mu \mathrm{m}, 780 \mu \mathrm{m}$ and $770 \mu \mathrm{m}$, i.e. spectral periods of $1.76 \mathrm{~cm}^{-1}, 1.78 \mathrm{~cm}^{-1}$ and $1.81 \mathrm{~cm}^{-1}$, thus well around the target value. A fourth group with the 20 remaining steps, labelled as Water or $\mathrm{H} 2 \mathrm{O}$ channel, has a thickness about $320 \mu \mathrm{m}$ (spectral period of $4,3 \mathrm{~cm}^{-1}$ or OPD of $2.3 \mathrm{~mm}$ ). Indeed, the interferoram at this OPD is more sensitive to the $\mathrm{H}_{2} \mathrm{O}$

\footnotetext{
${ }^{2}$ www.lynred.com/fr/produits/snake-sw

3 https://noxant.com
} 
content than at the nominal OPD, even though this sensitivity remains low (see Section 6.1). Neverheless, in order to collect data for further signal processing, it was decided to also measure the interferogram in this area. For each group, the OPD sampling is roughly $\lambda / 5$. The large gap between the OPD for $\mathrm{CO}_{2}$ and the ones for $\mathrm{H}_{2} \mathrm{O}$ forced us to etch two separate plates, and then to assemble them.

The interferometric plate for $\mathrm{CH}_{4}$ is monolithic, since only one OPD interval is targeted. Based on the periodicity of the spectral signature (see Figure 1), this OPD should be $1.02 \mathrm{~mm}$ and thus the plate thickness should be around $144 \mu \mathrm{m}$. However, the plate would be too thin and too breakable. We thus decided to double the thickness, at $288 \mu \mathrm{m}$. In a Fourier analysis, it means that we sample the first harmonics rather than the fundamental frequency of the $\mathrm{CH}_{4} \mathrm{spectral}$ signature. On the whole plate, the 80 steps span from $290 \mu \mathrm{m}$ to $300 \mu \mathrm{m}$ in thickness.

The main characteristics of the NanoCarb cameras are listed in Table 1.

Table 1 Main characteristics of the NanoCarb cameras

\begin{tabular}{|l|l|l|}
\hline & \multicolumn{1}{|c|}{ NanoCarb CO } & \multicolumn{1}{|c|}{ NanoCarb CH } \\
\hline Spectral band (on axis) & $\begin{array}{l}{[1606-1612] \mathrm{nm}} \\
{[6203-6228] \mathrm{cm}-1}\end{array}$ & $\begin{array}{l}{[1635-1653] \mathrm{nm}} \\
{[6050-6116] \mathrm{cm}^{-1}}\end{array}$ \\
\hline iFOV & $5 \mathrm{mrad}$ & $5 \mathrm{mrad}$ \\
\hline Useful number of pixels & $50 \times 50$ & $50 \times 50$ \\
\hline Useful FOV & $\pm 6.6^{\circ}$ & $\pm 6.6^{\circ}$ \\
\hline OPD / spectral period & $5.7 \mathrm{~mm} / 1.8 \mathrm{~cm}^{-1}\left(\mathrm{CO}_{2}-1\right.$ channel $)$ & $2.1 \mathrm{~mm} / 4.8 \mathrm{~cm}^{-1}$ \\
& $5.6 \mathrm{~mm} / 1.8 \mathrm{~cm}^{-1}\left(\mathrm{CO}_{2}-2\right.$ channel $)$ & \\
\hline Frame rate & $5.5 \mathrm{~mm} / 1.8 \mathrm{~cm}^{-1}\left(\mathrm{CO}_{2}-3\right.$ channel $)$ & \\
\hline Mass & $2.3 \mathrm{~mm} / 4.3 \mathrm{~cm}^{-1}\left(\mathrm{Water}^{\circ}\right.$ channel $)$ & $20 \mathrm{~Hz}$ \\
\hline Volume & $20 \mathrm{~Hz}$ & $1.9 \mathrm{~kg}$ \\
\hline
\end{tabular}

\subsection{Visible camera}

In addition to the NanoCarb cameras, a color camera was also installed. This camera provides images of the scene which can be interpreted more easily than the SWIR images, thanks to the colors of the images and its finer spatial resolution: iFOV of $0.3 \mathrm{mrad}(3 \mathrm{~m}$ at $10000 \mathrm{~m}$ height), thus nearly 20 times finer than for the NanoCarb cameras. The images are $1024 \times 1024$ pixels wide, so that the FOV $\left( \pm 9.2^{\circ}\right)$ is quite the same than for the NanoCarb cameras, as well as the frame rate. Examples of images provided by this camera will be given on Figure 6 in Section 4.1. An automatic gain control allows to adapt to the high dynamics of the scene observed during a flight, but the images provided are not radiometrically calibrated.

\subsection{Aircraft integration}

The three cameras have been installed inside the cabin of the Falcon20. They are all set on a gyrostabilized mount (GSM) PAV80 from Leica. An IMU is also set on the GSM to provide attitude data that can be used for image registration and georeferencing. The use of this GSM was initially decided to host on the same plate NanoCarb cameras and Mamap, the reference sensor which is non imaging and therefore requires a stabilized line-of-sight. This GSM was retained even though, unfortunately, the presence of Mamap has been given up due to the travel restrictions imposed to face the Covid pandemic.

Figure 2 (left) shows the two NanoCarb and the visible cameras on the interface plate with the GSM and Figure 2 (right) their placing on the GSM on board the F20. 

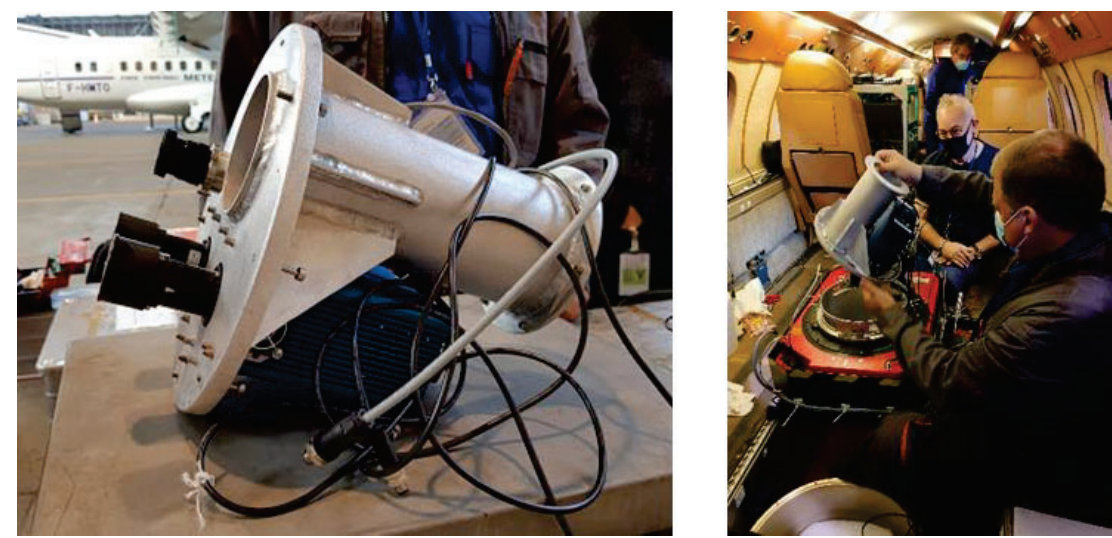

Figure 2. Left: the two NanoCarb and the visible cameras on the interface plate with the GSM; the large metallic cylinder was to host the optical head of Mamap. Right: placing of the cameras on the GSM(red and black) on board the F20. At the very foreground appears the mechanical structure for SpexAirborne.

The cameras were piloted by a single NanoCarb operator through a user interface. The goals of this interface were multiple:

- set the acquisition parameters (integration time, frame rate, acquisition duration, comments) and launch the acquisitions (including the GSM);

- check the good behavior of the instruments (temperatures of the optics and FPAs, network connection, available space on the disk);

- visualize the image in real-time.

The visualization of the visible images allows to check that the scene is the expected one, and to roughly estimate the cloud coverage. The visualization of the Swir images allows to choose the correct integration time. As all the thumbnails of one camera are very similar, only one thumbnail (per camera) is displayed, for a better interpretation by the operator. However, the histogram of the whole FPA is also displayed with a tunable Look-Up Table, for a finer setting of the integration time.

An example of the user interface is shown on Figure 3 (left). On Figure 3 (middle and right) are photos of the F20 cabin, the middle image being taken from the cockpit (Spex is too on the foreground and is out of the field). Since there was no Mamap operator, a second seat was available for NanoCarb, so that one NanoCarb operator and one NanoCarb observer could fly together. 

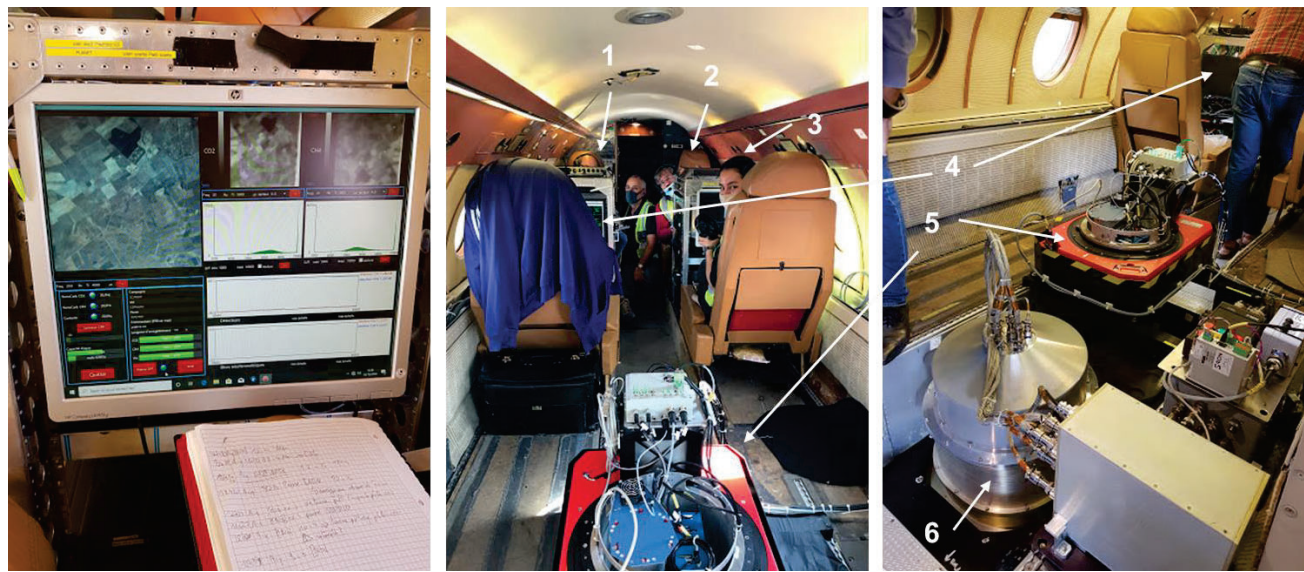

Figure 3. Left: NanoCarb user interface, seen from the NanoCarb operator seat. The image on the left is the visible image, while the two black and white images on the right are one thumbnail from the $\mathrm{CO}_{2}$ and the $\mathrm{CH}_{4}$ cameras. Middle and right: inside of the F20 1: Safire operator, 2: NanoCarb operator, 3: NanoCarb observer, 4: Spex operator, 5: GSM with the NanoCarb cameras, 6: SpexAirborne.

\section{CAMPAIGN PROGRESS}

\subsection{General view of the airborne SCARBO campaign}

The airborne campaign took place in October 2020, from Francazal airport, near Toulouse in France. Two sorts of targets had been defined for this campaign, to fulfill the initial purposes of the campaign (see Section 1.3). The aerosol targets were the Pô Valley, in Italy, and South of Spain, and the $\mathrm{CO}_{2}$ targets were $\mathrm{CO}_{2}$ plumes from power plants in Germany and Poland (see Figure 4). Thanks to the long range of the F20, the base airport was Francazal all along the campaign, even though a refueling stop was needed for the most far-off targets.

For "aerosol" targets, due to Spex multi-angle view principle, the flight pattern is a straight line at $10 \mathrm{~km}$ height. For the " $\mathrm{CO}_{2}$ " targets, it was expected to have both a straight line at $10 \mathrm{~km}$, to acquire aerosol data, and a whiskbroom pattern at $3 \mathrm{~km}$ to cross several times the plume and to map a "box" of a few tens of kilometers side. The size and location of this box with respect to the power plant was evaluated by Bremen University the day before the flight, taking into account the expected emitted $\mathrm{CO}_{2}$ flux, and the wind speed and direction.

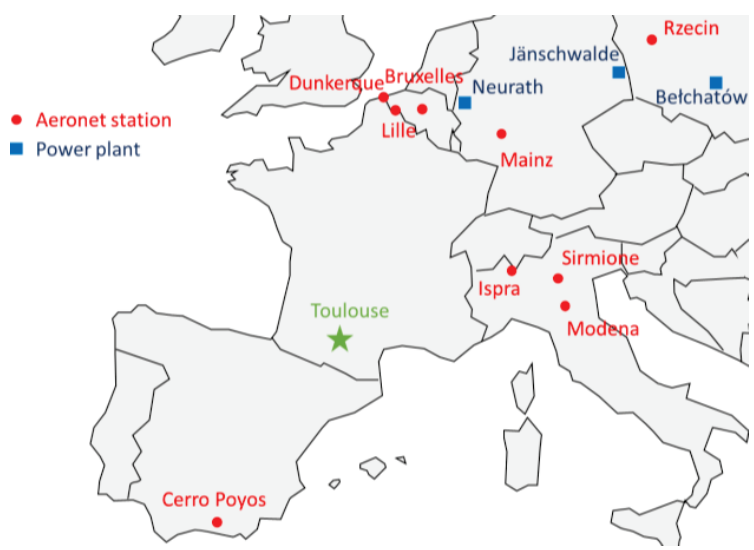

Figure 4. Possible targets initially defined for the SCARBO campaign 
Unfortunately, various unwelcome events prevented to fly over most of the targets: minor issues in the aircraft but which required immobilization while waiting for the spare part, bad weather conditions, or closed area from the air traffic control. Consequently, only five flights were conducted: one test flight, three "aerosol" flights, and one " $\mathrm{CO}_{2}$ " flight on the very last day, over Bełchatów, but the weather conditions over the thermal power plant proved to be completely cloudy.

Table 2 Summary of the flights performed during SCARBO campaign (maps are from GoogleEarth)

\begin{tabular}{|c|c|c|c|}
\hline Date & Target & $\begin{array}{l}\text { Flight height } \\
\text { over the target }\end{array}$ & Map \\
\hline $\begin{array}{l}9^{\text {th }} \text { October } \\
\text { (morning) }\end{array}$ & $\begin{array}{l}\text { test flight, over } \\
\text { the Garonne } \\
\text { Valley (France) }\end{array}$ & & \\
\hline $\begin{array}{l}9^{\text {th }} \text { October } \\
\text { (afternoon) }\end{array}$ & $\begin{array}{l}\text { "aerosol" flight, } \\
\text { over the South of } \\
\text { Spain }\end{array}$ & $10000 \mathrm{~m}$ & \\
\hline $17^{\text {th }}$ October & $\begin{array}{l}\text { "aerosol" flight, } \\
\text { over the Pô } \\
\text { Valley (Italy) }\end{array}$ & $10000 \mathrm{~m}$ & \\
\hline
\end{tabular}




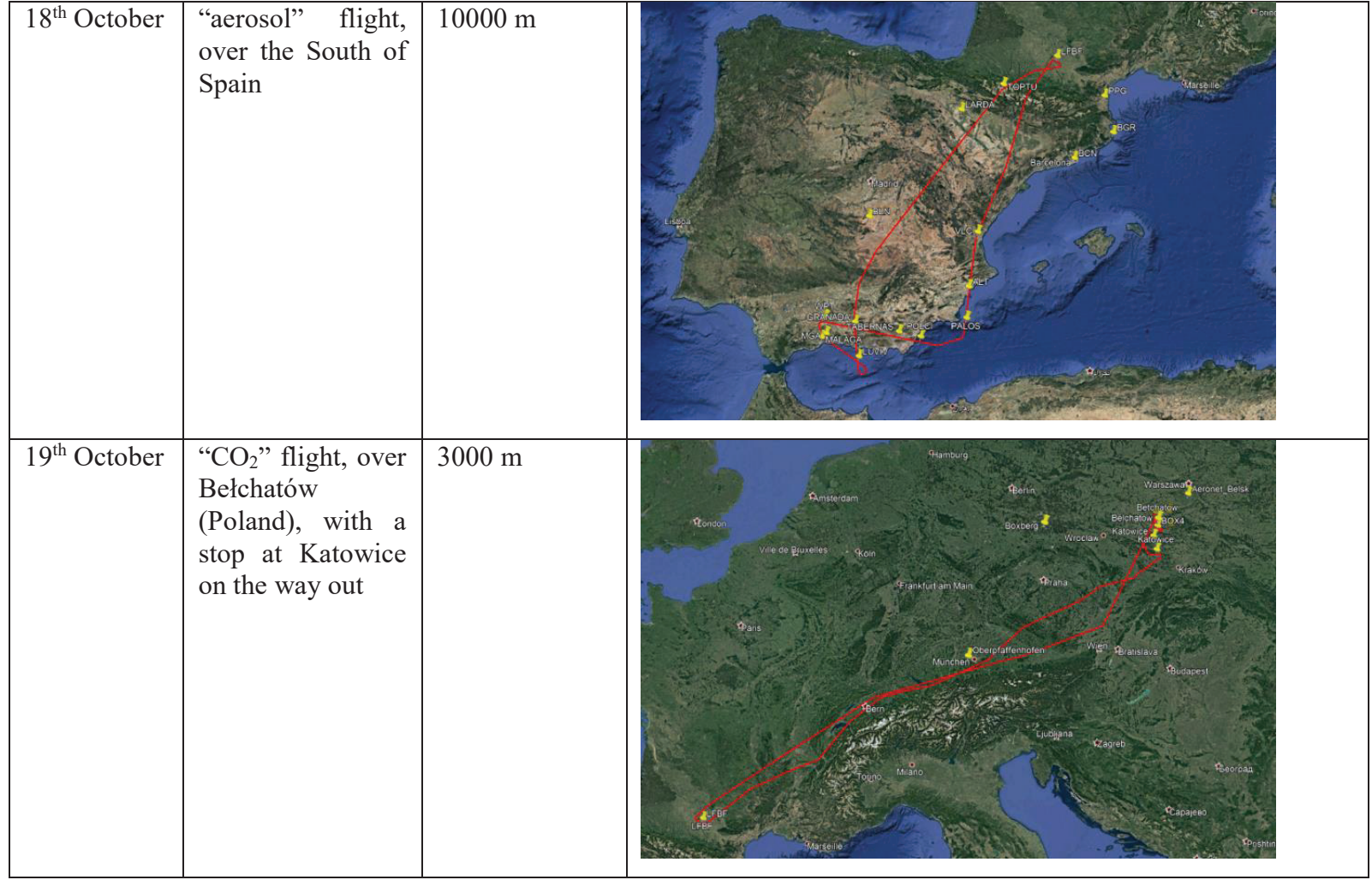

\subsection{NanoCarb data}

NanoCarb has proved during this campaign to work very well: no major problem on the cameras has occurred, and a lot of data have been acquired, either over the targets or during the transit phases. Even though we did not have the possibility to image a thermal power plant and its plume, very different scenes have been imaged which will help us to develop NanoCarb image processing and to estimate its performance:

- $\quad$ land, sea, clouds,

- flat landscapes, hills, mountains,

- $\quad$ cities, fields, lakes, rocky or snowy mountains, forests,

- $\quad$ either sunny or more or less cloudy.

In addition to these images, we have also acquired background images, at the beginning and the end of each flight, when the hatch was closed. These background images were acquired at various integration time to separate the offset voltage $\mathrm{d}_{\text {offset }}$ from the background current $\mathrm{d}_{\text {current }}$ (see [10]). Figure 5 shows the difference between the backgrounds acquired in the laboratory and the ones acquired during flight. Except for the first scientific flight, the background current is very stable and close to the one measured in the laboratory: for a $10 \mathrm{~ms}$ integration time, the difference is about 1 ADU. This makes us confident about the baffling inside the aircraft. As expected, the variation of the voltage current is higher (up to 5 ADU): we thus used these backgrounds to correct the images (see Section 4.1). 

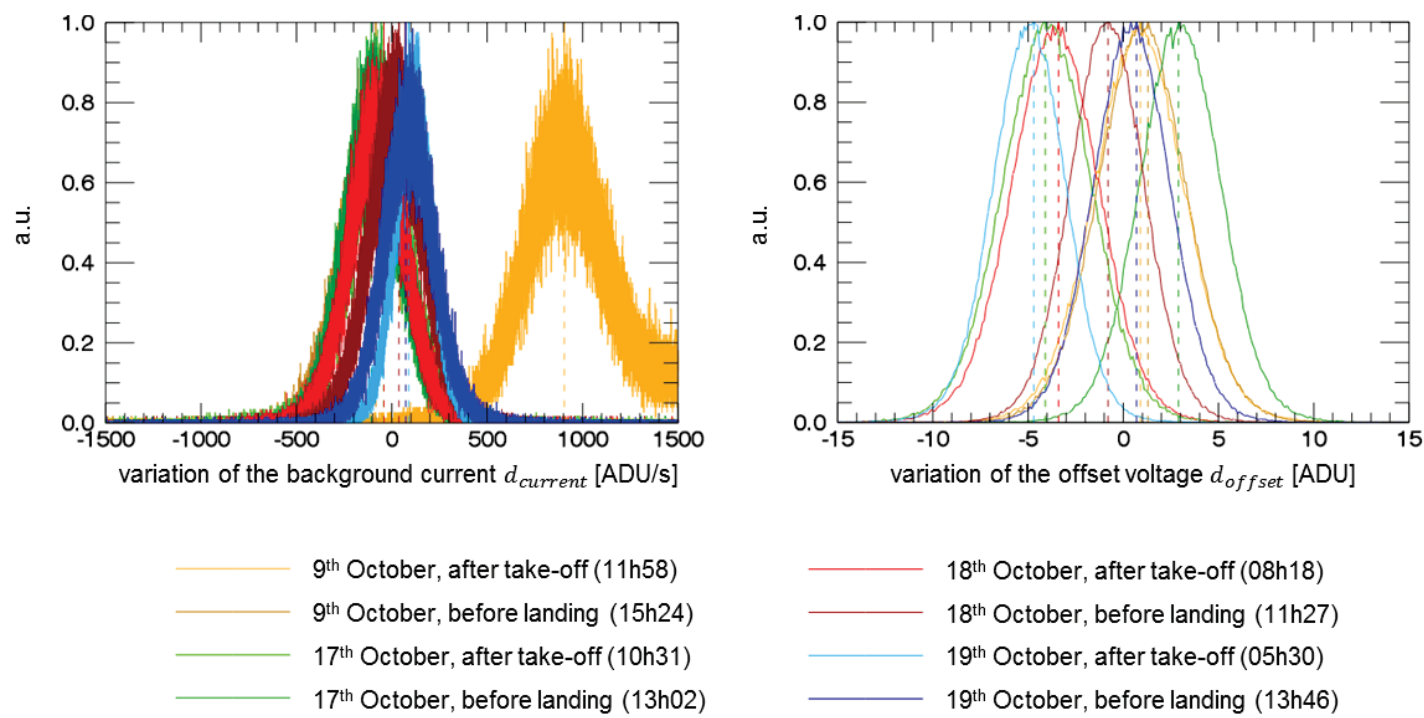

Figure 5. Normalized histogram of the difference between background measured in laboratory and background measured in flight Left: background current. Right: offset voltage

\section{DATA PRODUCT AND MODEL}

End to end conception then operation of the first airborne NanoCarb demonstrator was a good opportunity to develop and experience calibration and data processing procedure over real acquisitions. Following a description of each data level, introducing formalism, model, then encountered data processing issues.

\subsection{Lo Snapshot raw image}

For each camera, raw data consists in snapshot focal plane intensity. This L0 product is an image of 640x512 pixels, expressed in grey level (ADU) over a 14 bits analog to digital conversion range. Figure 6 shows L0 frame example from the campaign for the two bands, $\mathrm{CO}_{2}$ and $\mathrm{CH}_{4}$. Also presented are the thumbnails partition over the detector and the different interferometric channels. At L0 level, pixel means a physical pixel of the detector.

Acquired L0 raw signal s can be expressed as follows for a given pixel:

$$
s=d_{\text {offset }}+t_{i} \times\left[d_{\text {current }}+\frac{G}{\kappa} \int \eta(\sigma) L(\sigma) d o\right],[\mathrm{ADU}]
$$

Where $\mathrm{d}_{\text {offset }}$ and $\mathrm{d}_{\text {current }}$ are respectively offset and gain part of the dark signal, $\mathrm{t}_{\mathrm{i}}$ the integration time, $\mathrm{G}$ the geometric etendue, $\kappa$ the detector quantization step, $\eta(\sigma)$ the full system spectral efficiency at wavenumber $\sigma$ (or normalized Instrumental Spectral Response Function - ISRF -), and L the spectral radiance of the observed scene, function of geophysical parameters $\left(\mathrm{CO}_{2}\right.$ or $\mathrm{CH}_{4}$ columns, albedo, pressure and temperature profiles, aerosols, water vapor column, and so on).

L cannot be analytically derived from $\mathrm{s}$ due to the spectral integration over the spectral range of sensitivity of the instrument. Consequently, we used the expression (1) to first build a model coupled with radiative transfer, then retrieve atmospheric parameters implementing inverse method as follows:

(i) L0 frames processing to remove dark level, to correct Photon Response Non Uniformities (PRNU), to identify bad pixels, then to convert digital signal into radiometric unit:

$$
s^{\prime}=\frac{s-\left(d_{\text {offset }}+t_{i} \times d_{\text {current }}\right)}{t_{i} \times \kappa^{\prime}},\left[\text { photon } /\left(\mathrm{s} . \mathrm{m}^{2} . \mathrm{strd}\right)\right]
$$


(ii)

Corrected signal simulation:

$$
\tilde{s}=\int \eta^{\prime}(\sigma) \mathrm{L}(\sigma) \mathrm{d} \sigma,\left[\text { photon } /\left(\mathrm{s} . \mathrm{m}^{2} . \mathrm{strd}\right)\right]
$$

Where $\kappa^{\prime}$ and $\eta^{\prime}$ are the experimental estimates of respectively radiometric gain and related normalized ISRF. More details about Expression (1) to (3) in [10], as well as experimental evaluation and calibration of $\kappa^{\prime}, \eta^{\prime}, \mathrm{d}_{\mathrm{offset}}$ and $\mathrm{d}_{\text {current }}$.

Some sources of uncertainties have been identified for this model at this time:

- Uncertainties about radiometric calibration, evaluated at $~ 1 \%$

- Offset level variation of the dark during the flight, observed between 5 to 10 ADU

- Pixel to pixel radiometric gain $\left(\kappa^{\prime}\right)$ variations, due to an identified mechanical component

- $\quad$ In addition, a very good reliability of the ISRF has been observed
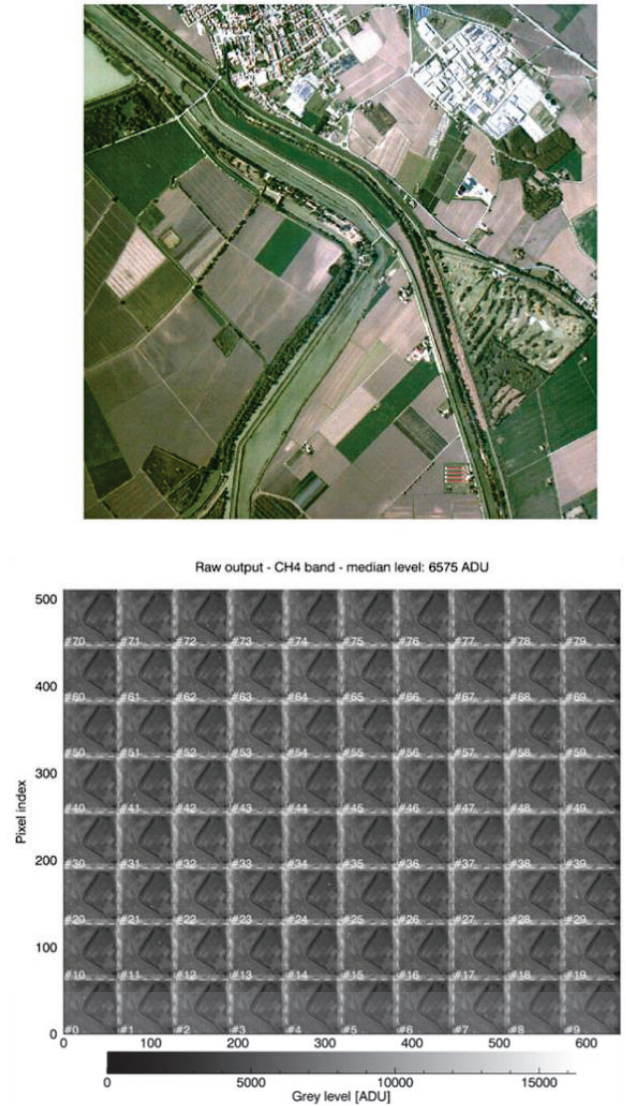
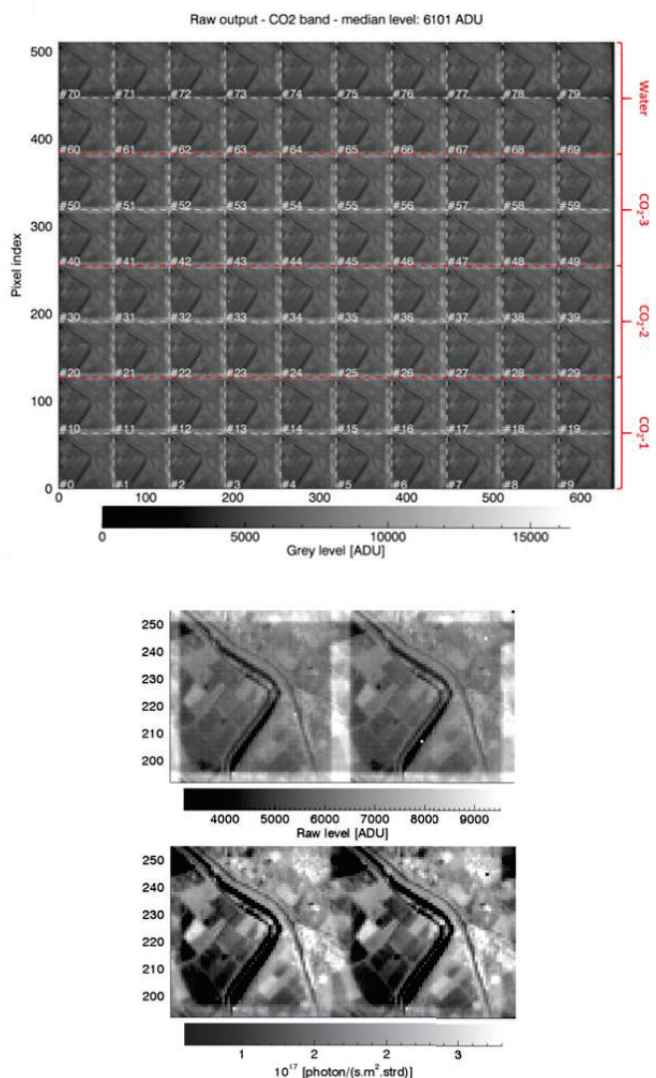

Figure 6. Top-left: context visible RGB picture from flight over Italy, October 17th 2020, between Adriatic sea and Modena, at $10 \mathrm{~km}$ of altitude. Top-right: $\mathrm{CO}_{2} \mathrm{~L} 0$ raw frame. Bottom-left: $\mathrm{CH}_{4} \mathrm{~L} 0$ raw frame. Superimposed thumbnail indexation and interferometric channels. $\mathrm{CH}_{4}$ band has a single interferometric channel when $\mathrm{CO}_{2}$ band has four. $\mathrm{CH}_{4}$ camera is rotated by $180^{\circ}$ compared to $\mathrm{CO}_{2}$. Picture is consequently reversed. Bottom-right: detail of the $\mathrm{CO}_{2}$ raw image (top), corrected then expressed in radiometric unit (bottom).

\subsection{L1a interferograms}

L1a data is the collection of snapshot, radiometrically calibrated, single elementary field of view (ifov) interferograms, extracted from processed snapshot L0 frame. At L1a level, pixel means elementary field of view or ground pixel. 
Main processing from L0 corrected frame to L1a interferograms is a spatial registration of the thumbnails, interpolating intensity over a common grid (Field of View - FoV - in degree). Consequently, from the 2D L0 frame, we obtain a 3D cube of spatially registered thumbnails as illustrated on Figure 7. Some L1a interferograms are plotted Figure 7-right.
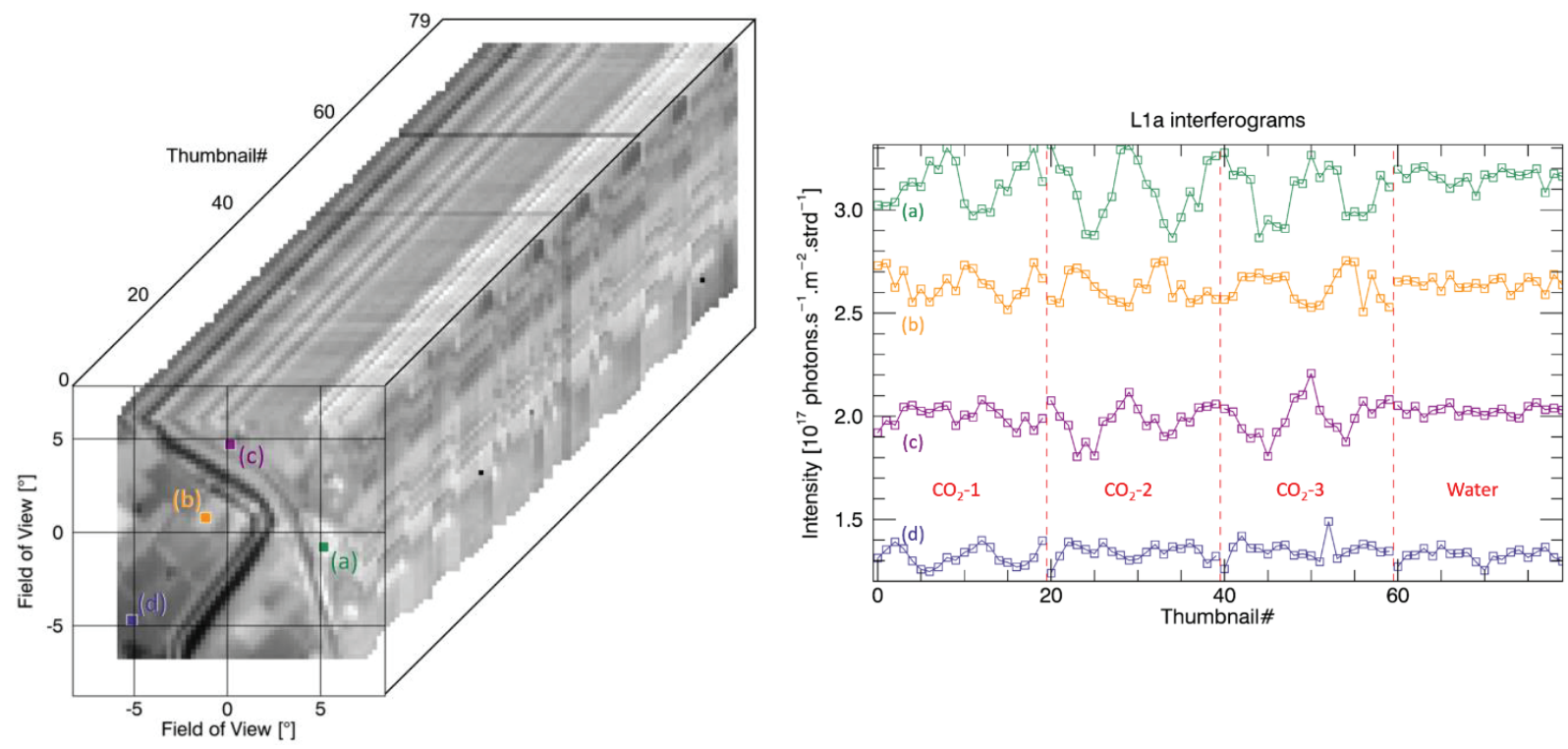

Figure 7. Left: Snapshot L1a cube of registered and radiometrically calibrated thumbnails. Right: some L1a interferograms extracted from this cube. Each curve's color corresponds to a colored point over the field of view of the left cube.

L1a interferogram computation requires a geometric calibration of the instrument, associating the corresponding ifov in each thumbnail. Some details about this calibration step can also be found in [10].

We still have to estimate the accuracy of the inter-thumbnail spatial registration. At this preliminary step of SCARBO data analysis, we observe issues from sharp transition over scenes between areas of hugely different albedo (water and artificial soil for example): the accuracy of registration or interpolation may not be fine enough to prevent artefact over the transitions. Consequently, we focus over homogeneous albedo areas, while accuracy and processing are improved in parallel.

\subsection{L1b}

L1b interferogram is a time sequence of co-localized interferograms at ground, acquire while the imaged scene is moving in the instrument field of view as illustrated on Figure 8.

L1b extraction requires to estimate sub-pixel displacement between consecutive frames. At this time, we mainly use an inter-correlation between the consecutive L0 frames, evaluating a simple translation. Rotation may be taken into account to improve registration of acquisition sequence, and correct aircraft maneuvers.

At $10 \mathrm{~km}$ of altitude (50 m per pixel), with a ground velocity of $240 \mathrm{~m} / \mathrm{s}$, and an acquisition framerate of $20 \mathrm{~Hz}$, about 220 co-localized interferograms can be extracted for a given pixel at ground. 


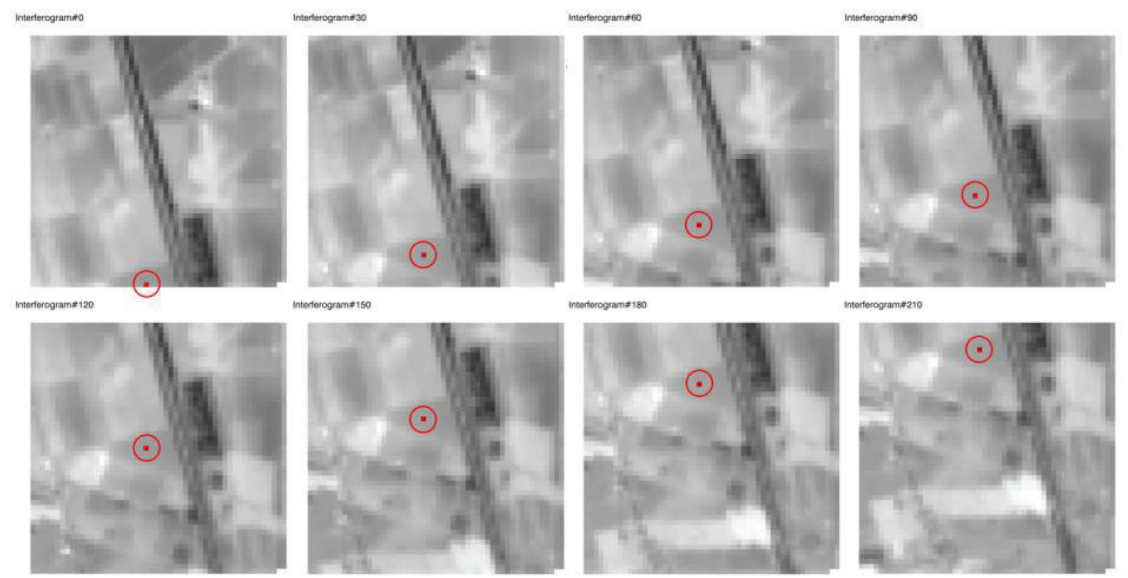

Figure 8. Time sequence of acquisitions over the $\mathrm{CO}_{2}$ band, showing successive panchromatic $\mathrm{CO}_{2}$ images. Panchromatic frame is defined as the averaged of all the thumbnails for each band. L1b time series of interferograms are extracted as an example for the surrounded red point at ground from the time sequence of L1a cube.

\section{4. $\mathrm{L} 2$}

L2 data product is the $\mathrm{CO}_{2}$ and $\mathrm{CH}_{4}$ dry air column-averaged mole fraction value for a given ifov, retrieved from $\mathrm{L} 1 \mathrm{~b}$ interferogram series.

The way to obtain L2 data product from L1b data is still under study. Would it be better to retrieved dry air columnaveraged mole fraction separately from each interferogram? At this point, each single L1a interferogram from L1b time sequence is inversed to retrieve single ifov, snapshot L2 products. Then, obtained time sequence of L2 products are averaged to improve signal to noise ratio.

On the other hand, optical path in the atmosphere and thus absolute column retrieval is difficult without $\mathrm{O}_{2}$ dedicated band or onboard reference instrument. Consequently, we are considering a normalization of the $\mathrm{CO}_{2}$ column by the $\mathrm{CH}_{4}$ one, described as the "Proxy method" in [12], and applied for MAMAP instrument in [7].

In a further step, integration of the SPEX inflight data for aerosol monitoring in the $\mathrm{CO}_{2} / \mathrm{CH}_{4}$ retrieval will be studied within the SCARBO consortium.

\section{L1 FORWARD MODEL}

\subsection{Method}

We are testing here the reliability of the model presented in Section 4.

Systematic processing of the campaign data is still out of scope as several additional months are required. We are rather working on particular scenes selected as a way of simplicity. As introduced in the previous section, we consider on this paper a scene from a flight over Italy between Adriatic Sea and Modena the 17th October, 11.50am UT. We did not experience critical instrumental issue during this flight. In addition, the homogeneous, large fields, without any relief, observed in this region are well suited to assess our algorithms and calibration pipelines.

Both $\mathrm{CO}_{2}$ and $\mathrm{CH}_{4}$ column retrieval is one of the high end objectives of the data exploitation. In this paper, we are still focusing on the instrument model building and preliminary data analysis, over $\mathrm{CO}_{2}$ band. To assess model reliability, a simple strategy is followed:

(i) Simulating terrestrial radiance spectra in the FoV of the instrument with arbitrary parameters, coupled with the NanoCarb model described Equation 3, to obtained simulated L1a interferograms in any pixel. 
(ii) Adjusting mean level of the models to fit the one of the extracted L1a interferograms, without changing atmospheric parameters.

(iii) Analyzing residual.

In the following sub-sections, we will first present qualitative comparisons between data and model, then quantify the residuals of fitting. Residual between this fitted model and extracted L1a interferograms will be analyzed with the partial derivative study on the next section.

\subsection{Qualitative observations}

Following the previously explained approach, we are producing here synthetic images to be compared with data. Expression 3 is implemented to fit extracted interferograms. Then, simulated L1a interferograms is reformed as a 2D image to be compared with processed L0 frame, as illustrated on top of Figure 9.

As expected within our brutal fitting method, synthetic and acquired frames are qualitatively almost similar. Nevertheless, interferometric information cannot be observed at this level: the relevant signal variations are about a few percent of the intensity, while the images are dominated by the scene dynamic (up to $500 \%$ ).

A common method to make apparent interferometric information over L0 frame is to normalized each thumbnail by the panchromatic picture - defined as the mean of all the thumbnails -. On bottom of Figure 9 is presented a comparison between such normalized frame and simulation. Model adequacy with data is promising:

- Expected 1-10\% ranged signal ring variations induced by atmosphere absorption is well present on the three $\mathrm{CO}_{2}$ channels.

- Shape of the Fabry-Perot induced rings are well suited between simulation and data, demonstrating a good stability of the interferometric core of the instrument, one of the critical component.

- Good reliability of the amplitude of the Fabry-Perot rings between simulation and data.

- Flat signal over water channel is also nominal according to the model.

Nevertheless, this view is also helpful to identify some instrumental induced issues:

- Some dusts over the optics and aircraft's window can be observed as "moving" dark points from one thumbnail to another.

- Some artefacts induced by the thumbnail registration can be observed along the imaged river (sharp transition between low to high albedo).

- Vignetting over the water channel (top raw of thumbnails) is present, probably induced by a drift of the entrance diaphragm during the mission. 

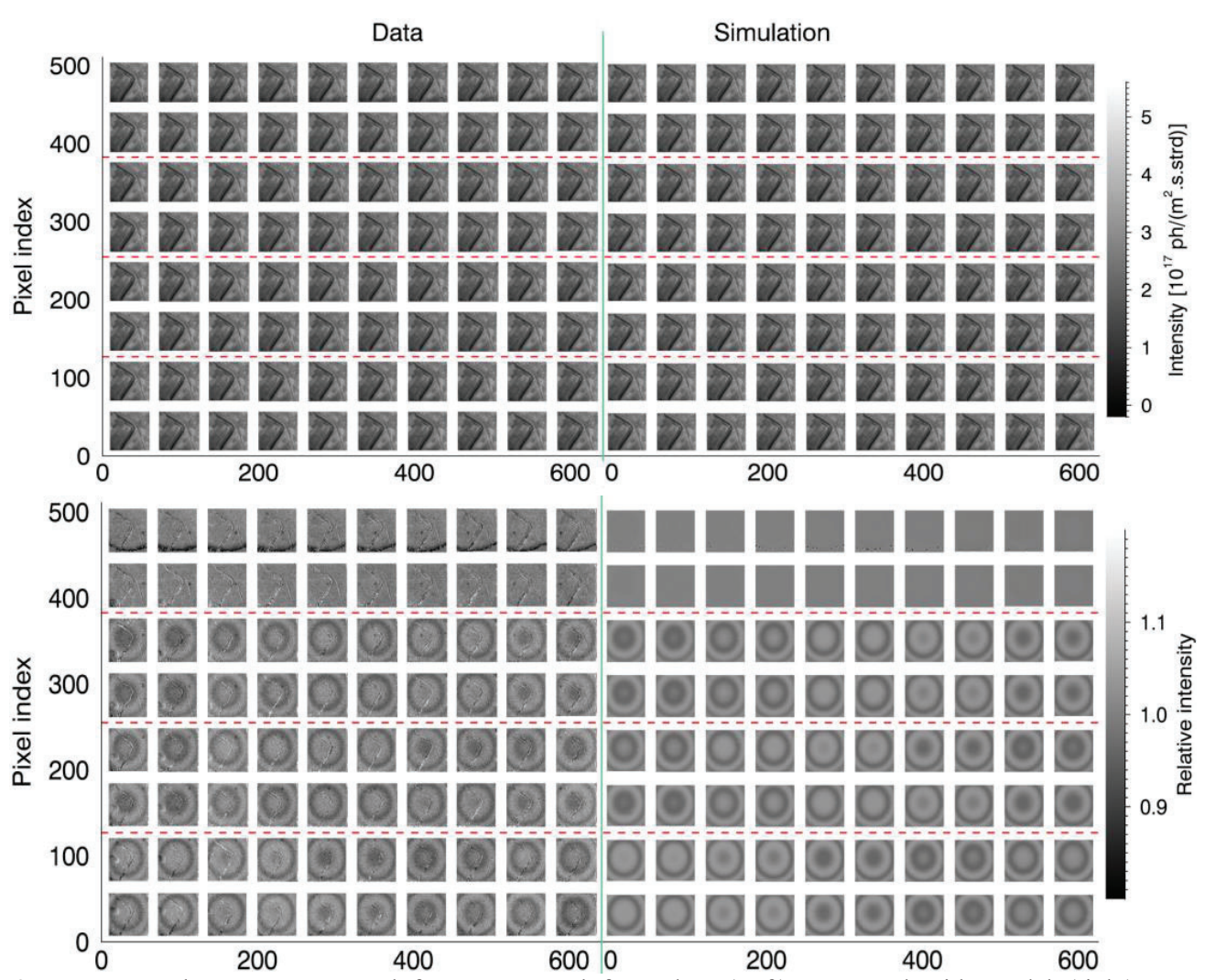

Figure 9. Top: Snapshot $\mathrm{CO}_{2}$ processed frame extracted from data (Left) compared with model (right). Bottom: a normalization by panchromatic picture make apparent interferometric signature of the atmospheric absorption. Radiometric model shows a well adequacy with data.

\subsection{Quantitative analysis of L1a interferogram modelling}

From the overview at L0 level of the previous sub-section, we are moving here at L1a level, detailing and quantifying model adequacy in the FoV.

Illustrated on Figure 10 are some fitted $\mathrm{CO}_{2}$ L1a interferograms in the FoV (as spotted on Figure 7). Red dashed lines split the different interferometric channels. Residual is defined as the difference between L1a model and data. Table 3 shows quantification of the residual for the 4 ground pixels of Figure 7, as well as related standard deviation and ratio with the mean level of the interferogram (so-called fitting error or residual fitting). These arbitrary examples show a relative residual of fitting ranged from 1.5 to $2.5 \%$.

We generalize this study to the whole field of view on Figure 11, showing maps of relative residual of fitting for the different interferometric channels:

- We don't identify any huge disparities between the different $\mathrm{CO}_{2}$-dedicated interferometric channels, despite the water one which presents an important vignetting-induced excess of fitting error as highlighted before.

- Residual background seems to be ranged around $2 \%$ of error and homogeneous in the FoV.

- Excess of error according to this background is located 1) along brutal transitions between dark and bright areas, 2) over bad pixels and 3) in dark areas.

Finally, Figure 12 plots this fitting error as a function of the albedo. We estimate the albedo at the first order by multiplying the albedo used in our atmospheric model by the fitting coefficient, which adjusts the mean levels. Figure 12 
shows first a signal-to-noise-ratio-driven decrease of the fitting error with the albedo until albedo $=0.15$, from which the residual does not change anymore from $2 \%$. We will analyze this value in the next section.

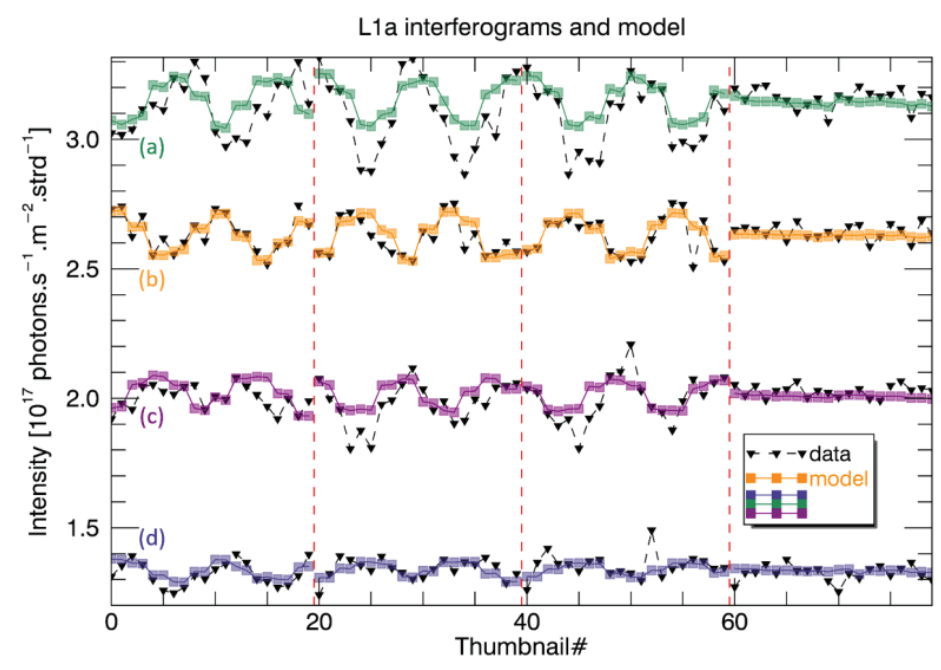

Figure 10. Some L1a interferograms in the field of view and associated models.

Table 3 Estimate of fitting residual for 4 L1a interferograms in the field of view. See Figure 7 and Figure 10.

\begin{tabular}{|c|c|c|c|c|}
\hline Data point & $\begin{array}{c}\text { Estimated } \\
\text { albedo }\end{array}$ & $\begin{array}{c}\text { Interferogram median } \\
\text { level }\left[10^{17}\right. \\
\left.\text { ph } /\left(\text { s.m }^{2} . \text { strd }\right)\right]\end{array}$ & $\begin{array}{c}\text { Standard deviation of the } \\
\text { fitting residual }\left[10^{17}\right. \\
\left.\left.\text { ph/(s.m } \text { m }^{2} . s t r d\right)\right]\end{array}$ & $\begin{array}{l}\text { Ratio (relative } \\
\text { residual or } \\
\text { fitting error) }\end{array}$ \\
\hline (a) & 0.29 & 3.148 & 0.078 & $2.46 \%$ \\
\hline (b) & 0.24 & 2.632 & 0.039 & $1.46 \%$ \\
\hline (c) & 0.18 & 2.012 & 0.055 & $2.75 \%$ \\
\hline (d) & 0.12 & 1.335 & 0.036 & $2.69 \%$ \\
\hline
\end{tabular}



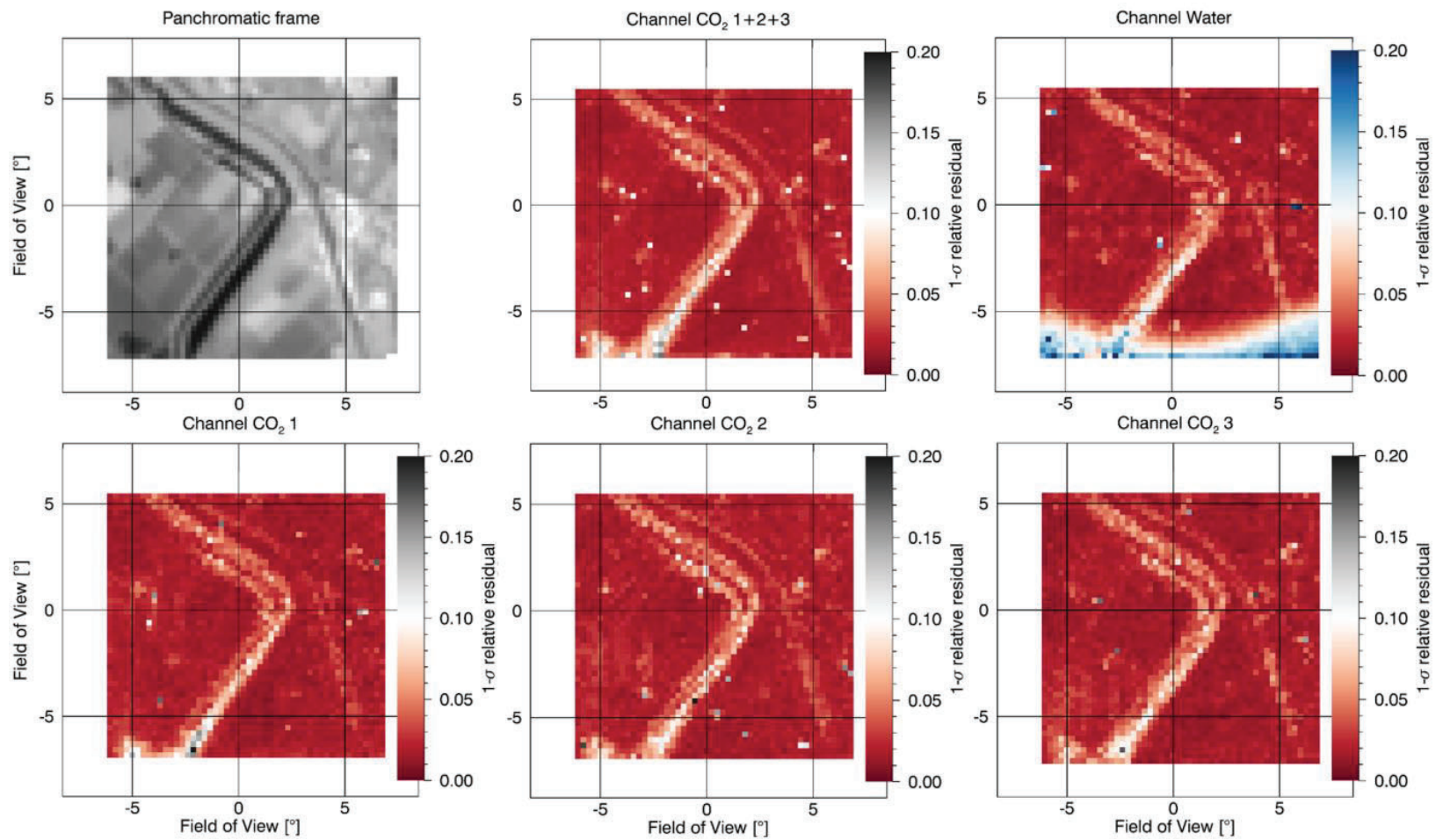

Figure 11. Relative residual shown over the field of view, over the different interferometric channels of the $\mathrm{CO}_{2}$ band.

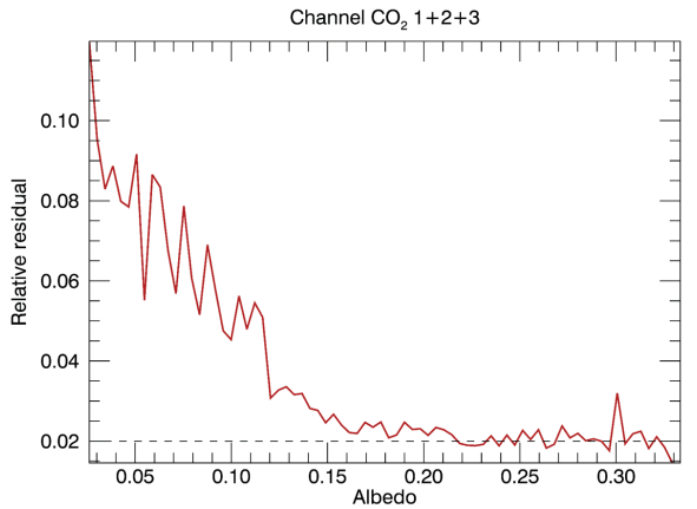

Figure 12. Relative residual plotted as a function of the estimated albedo, for the three $\mathrm{CO}_{2}$ channels of the $\mathrm{CO}_{2}$ band.

\section{STUDY OF PARTIAL DERIVATIVES}

Reliability of the model seems to be radiometrically confirmed by the experimental: we apply it here to derive expected sensitivity.

Using model Expression (3), laboratory characterizations and radiative transfer model, we provide a draft of a study of partial derivative for the main atmospheric parameters, then we derive expected sensitivity in the situations we encounter during the campaign, previously introduced. 
We estimate the normalized partial derivative of L1a intensity $\tilde{s}$ for a given pixel according to the atmospheric parameter $\mathrm{X}$ with finite variation approximation as follows:

$$
\frac{\partial \tilde{s}}{\partial X} \approx \frac{\tilde{s}(X+\partial X)-\tilde{s}(X)}{\operatorname{median}(\tilde{s}(X))}
$$

The different used atmospheric parameters in our model are listed on Table 4, as well as finite variations $\partial \mathrm{X}$.

Table 4 Atmospheric parameters used to perform radiative transfer calculations, and associated finite variations related to partial derivative estimate.

\begin{tabular}{|c|c|c|}
\hline X parameter & Reference & $\partial X$ \\
\hline $\begin{array}{l}\mathrm{CO}_{2} \text { total } \\
\text { column }\end{array}$ & $\begin{array}{c}\text { TIGR2000 V2 } \# 925 \\
\text { scale factor } \times 1.0\end{array}$ & $\begin{array}{c}\text { Total column scale } \\
\text { factor } \times 1.1\end{array}$ \\
\hline $\begin{array}{r}\mathrm{CH}_{4} \text { total } \\
\text { column }\end{array}$ & $\begin{array}{l}\text { TIGR2000 V2 \#925 } \\
\text { scale factor } \times 1.0\end{array}$ & $\begin{array}{l}\text { Total column scale } \\
\text { factor } \times 1.1\end{array}$ \\
\hline $\begin{array}{r}\text { Water total } \\
\text { column }\end{array}$ & $\begin{array}{l}\text { TIGR2000 V2 } \# 925 \\
\text { scale factor } \times 1.0\end{array}$ & $\begin{array}{l}\text { Total column scale } \\
\text { factor } \times 1.1\end{array}$ \\
\hline Surface pressure & $1013 \mathrm{hPa}$ & $+10 \%=1114.3$ \\
\hline Surface albedo & 0.2204 & $+10 \%=0.2424$ \\
\hline
\end{tabular}

\section{1. $\mathrm{CO}_{2}$ Band:}

In the followings, we are simply presenting analysis for a single pixel on the center of the field of view, for a nominal albedo of 0.22 , and operational parameters used during the Italy flight (exposure time $12 \mathrm{~ms}$ over $\mathrm{CO}_{2}$ band, $5 \mathrm{~ms}$ over $\mathrm{CH}_{4}$ band, framerate $20 \mathrm{~Hz}$ ).

Figure 13 presents partial derivatives for $\mathrm{CO}_{2}$, water and albedo on the $\mathrm{CO}_{2}$ band. Surface pressure partial derivative is not presented, since totally degenerative with albedo. As a reminder, the graph presents the different interferometric channels: channel $\mathrm{CO}_{2}-1$ for thumbnails number 0 to 19,20 to 39 for $\mathrm{CO}_{2}-2,40$ to 59 for $\mathrm{CO}_{2}-3$, and 60 to 79 for water. From this figure, we note two points.

- A variation of $+10 \% \mathrm{CO}_{2}$ on the total column induces more than 10 times higher variation of intensity than $+10 \%$ of $\mathrm{H}_{2} \mathrm{O}$, when $+10 \%$ of albedo induces a variation 10 times higher of signal than $+10 \%$ of $\mathrm{CO}_{2}$ (with this atmospheric model). Moreover, albedo is clearly not independent with $\mathrm{CO}_{2}$. This would probably be an issue for retrieval processing, and may require to apply a column normalization approach like Methane Proxy method.

- $\mathrm{CO}_{2}$ band 1 poorly affected by water as $\mathrm{CO}_{2}-3$ is mostly affected. As expected water band is not sensitive to $\mathrm{CO}_{2}$ but mostly to water, considering this atmospheric model.

Partial derivatives compared with 1-sigma noise level are plotted on Figure 14. Noise level is given for a single frame, and by averaging 10, 100 and 220 frames (L1b time sequence), considering SNR trend driven by photon noise. 220 is the maximum number of available frame at $10 \mathrm{~km}$ high and with $20 \mathrm{~Hz}$ acquisition framerate. These calculations can be summarized as follows:

- Albedo: On a single snapshot frame, $+10 \%$ albedo variation is higher than 10 times the 1 sigma level of a single frame

- $\mathrm{CO}_{2}:+10 \% \mathrm{CO}_{2}$ variation is around 5 times above the 1 sigma noise level by averaging 220 frames of the time sequence. We are Expecting 2\% sensitivity of the $\mathrm{CO}_{2}$ column on L1b level.

- Water: even averaging the maximum number of frames, $+10 \%$ variation of water is not above the 1 sigma noise level.

Preliminary conclusions of this study are the following: 
- Expected sensitivity of the $\mathrm{CO}_{2}$ column on L1b level is $2 \%$, given the chosen situation. Sensitivity could be improved by a fine inflight tuning of the exposure time and an increase of the framerate.

- $\mathrm{CO}_{2}$ band seems to be poorly affected by water. Question remains about utility of the water channel in this situation, and in more "wet" atmospheric scenarios.

- As albedo and $\mathrm{CO}_{2}$ column are degenerated parameters, attention should be paid to inversion strategy.

- In the previous section, we highlighted a global $2 \%$ fitting error on the field of view, around the nominal albedo level. This error is slightly higher than the theoretical snapshot 1 -sigma $1.2 \%$ noise-induced level we estimated here. Difference probably comes from the un-adjusted $\mathrm{CO}_{2}$ column. This last is degenerated with the albedo, and was not taken into account to fit the median levels.

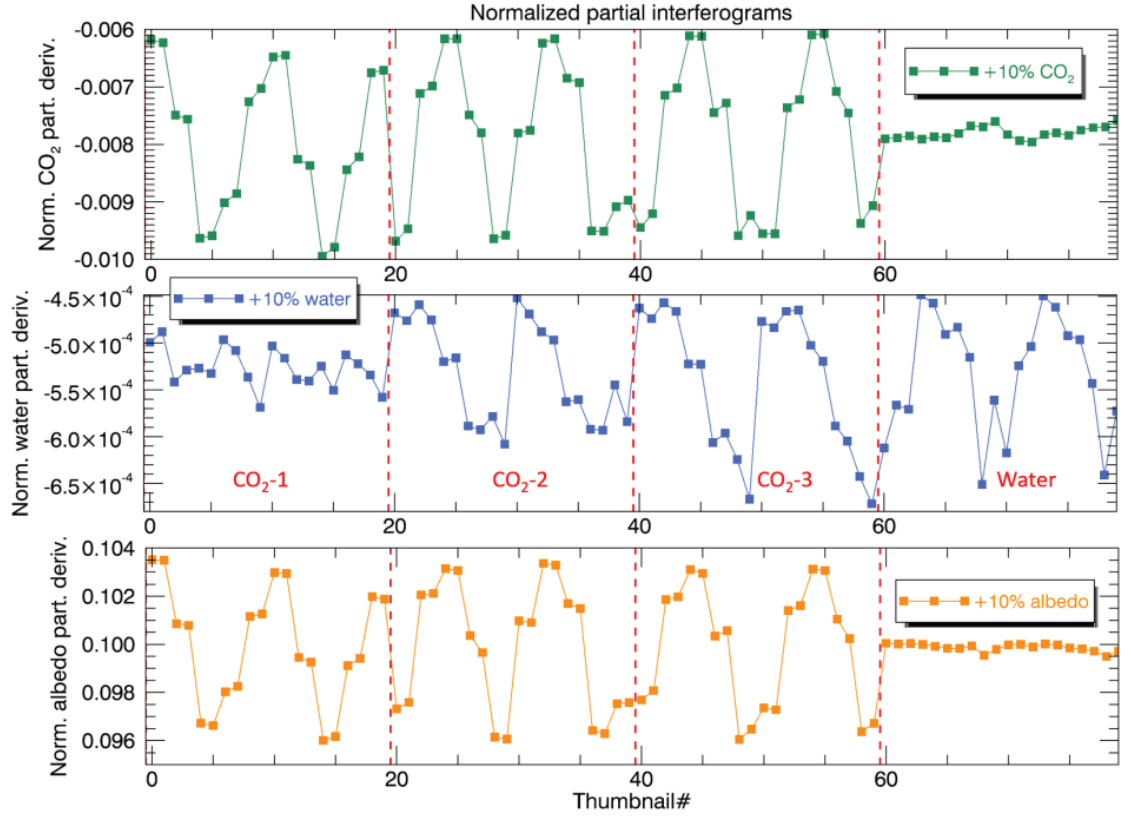

Figure 13. $\mathrm{CO}_{2}$ band partial derivatives of $\mathrm{L} 1$ a signal for $\mathrm{CO}_{2}$, water, and albedo, given a pixel on the center of the field of view and a nominal albedo of 0.22 .

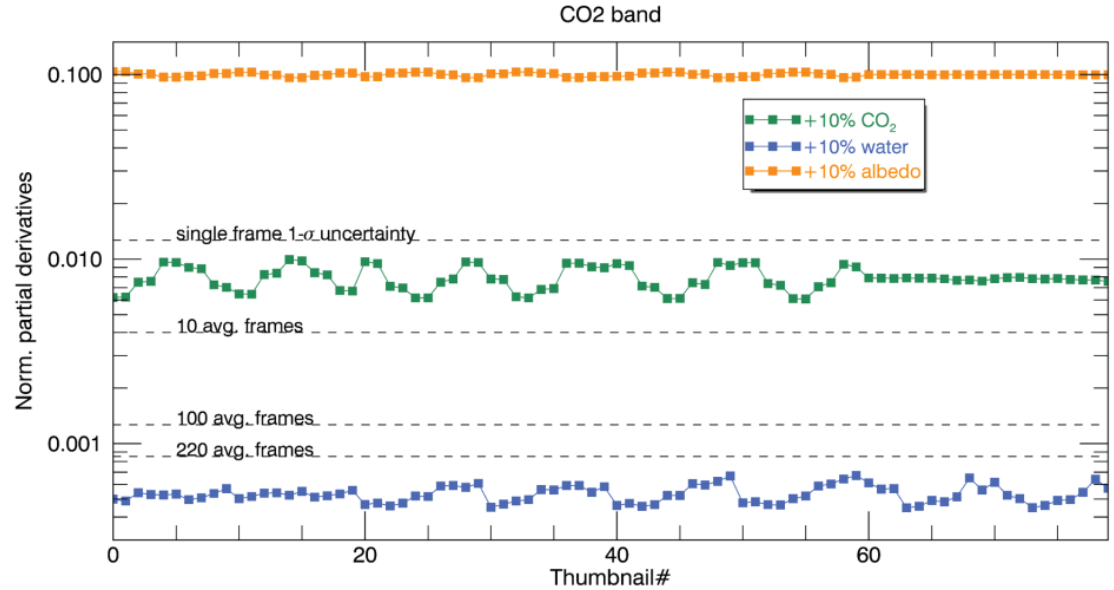

Figure 14. Comparison of the $\mathrm{CO}_{2}$ band partial derivatives with 1-sigma noise level of snapshot interferogram, then $\mathrm{L} 1 \mathrm{~b}$ averaged time series. Maximum number of available frames in L1b level is 220 at $10 \mathrm{~km}$ high with a framerate of $20 \mathrm{~Hz}$. 


\section{2. $\mathrm{CH}_{4}$ Band:}

Figure 15 directly shows partial derivatives over $\mathrm{CH}_{4}$ band compared with 1-sigma noise level. As the same way as before, noise level is given for a snapshot frame, and by averaging 10, 100 and 220 frames (L1b time sequence). The main comments about this figure are the following.

- Albedo: As on $\mathrm{CO}_{2}$ band, on a single snapshot frame, $+10 \%$ albedo variation is higher than 10 times the snapshot 1-sigma noise level.

- $\mathrm{CH}_{4}:+10 \% \mathrm{CH}_{4}$ variation is about 2 times above the 1-sigma noise level by averaging 220 frames of the time sequence. Consequently, we are expecting $5 \%$ sensitivity of the $\mathrm{CH}_{4}$ column at $\mathrm{L} 1 \mathrm{~b}$ level, in these conditions.

- Water: $\mathrm{CH}_{4}$ band is more sensitive to water than $\mathrm{CO}_{2}$ band, as a $10 \%$ variation of water column can be detected on complete $\mathrm{L} 1 \mathrm{~b}$ averaged sequence. In addition, water seems to be degenerative with $\mathrm{CH}_{4}$. Unfortunately, we did not provide water dedicated channel on this band, due to technological and time constraints. Particular attention should be paid to the water-induced bias in the following.

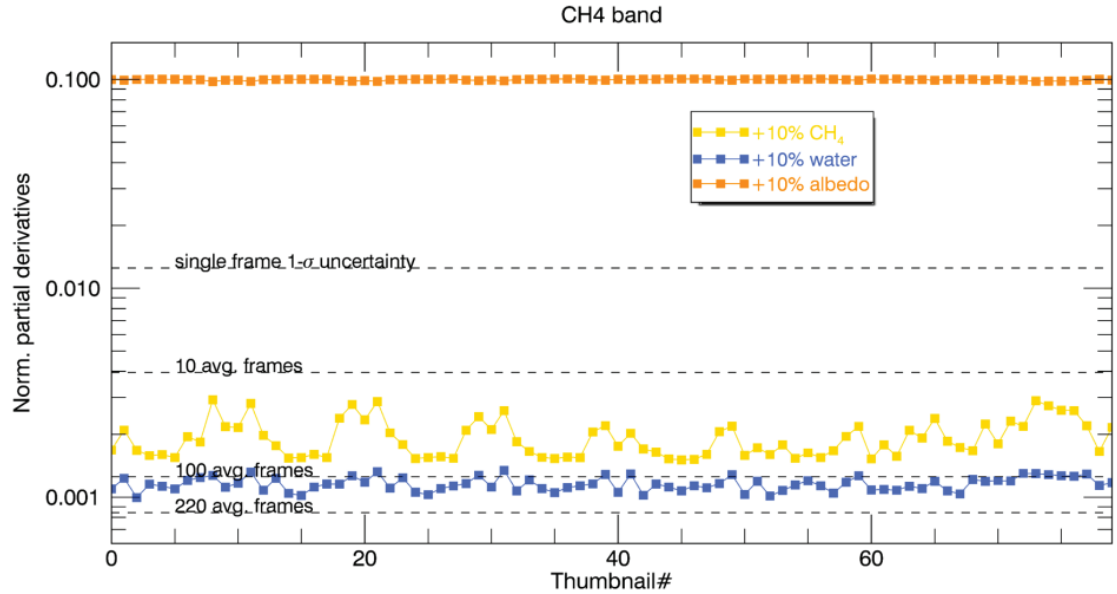

Figure 15. Comparison of the $\mathrm{CH}_{4}$ band partial derivatives with 1-sigma noise level of snapshot interferogram, then L1b averaged time series. Maximum number of available frames in L1b level is $\sim 220$ at $10 \mathrm{~km}$ high with a framerate of $20 \mathrm{~Hz}$.

\section{CONCLUSION}

Starting late 2017, the SCARBO project ambitioned to assess the feasibility of a GHG-dedicated constellation of small satellites based on the miniature NanoCarb concept. Three years later, we present the first NanoCarb prototype flight and measurement campaign within a challenging demonstration mission.

Thus, a TRL4 2-band prototype was integrated in a Falcon-20 aircraft from CNRS/SAFIRE facility, jointly to SPEX airborne, to flight over strong $\mathrm{CO}_{2}$ emitters in Europe. Even if we did not have the opportunity to fly over these special test cases during the campaign, we acquired a lot of data to be analyzed. Current related work in progress concerns especially data modelling, investigating laboratory calibrations and data processing. Our data modelling capability is crucial to be able to operate the instrument and to measure $\mathrm{CO}_{2}$ and $\mathrm{CH}_{4}$ column.

In this paper, we first demonstrated the airborne operability of the NanoCarb prototypes during these flights, without any major issue or trouble.

Then, showing the reliability of the calibration-based model with the data, we demonstrated a promising understanding of the instrument behavior. In addition, data quality seems to be nominal at this preliminary level of analysis.

With our simple forward model, we estimated a performance of about $1.5-2.5 \%$ of the $\mathrm{CO}_{2}$ total column and $5 \%$ of the $\mathrm{CH}_{4}$ total column in the conditions of the acquisitions. This is slightly too low to be able to comfortably detect a $\mathrm{CO}_{2}$ 
plume, as a 0.5 to $1.5 \%$ ranged sensitivity according to the background is expected. However, the control of the instruments was not optimal because the integration time was set by hand and did not allow us to make an optimal use of the dynamic range of the detectors. We estimate a potential margin of progress on the signal about a factor 1.5 to 3 on the two bands, given the situation. Moreover, an increase of the framerate, set to a "safe" value, may also improve the signal to noise ratio.

The presented work highlights also potential retrieval difficulties within this configuration, while some degeneracies have been identified between atmospheric parameters. This concern has to be carefully take into account to discuss and develop a retrieval strategy with SCARBO consortium members.

To conclude, we are building in parallel a spaceborne GHG sensor based on this first technological realization of a NanoCarb instrument, projecting and extrapolating our experience with this prototype. Space mission will be reviewed at the end of the project, mid 2021. So far, we are looking for a complementary opportunity to flight over $\mathrm{CO}_{2}$ plume or/and strong $\mathrm{CH}_{4}$ emitters, formally demonstrating NanoCarb performances.

\section{ACKNOWLEDGEMENTS}

This project has received funding from the European Union's H2020 research and innovation program under grant agreement No 769032 .

NanoCarb initiated in the framework of the LabEx FOCUS ANR-11-LABX-0013.

Work partly supported by the french RENATECH network.

\section{REFERENCES}

[1] P. Ciais and et al., "Towards a European operational observing system to monitor fossil CO2 emissions: final report from the expert group," COPERNICUS, EU publications, oct. 2015.

[2] N. Guérineau, E. Le Coarer, Y. Ferrec and F. De la Barrière, "Spectro-imageur multivoies à transformée de Fourier”. Patent WO2018/002558A1, 2018.

[3] Y. Ferrec, G. Bonnery, L. Brooker, L. Croizé, S. Gousset and E. Le Coarer, "NanoCarb part 1: compact snapshot imaging interferometer for CO2 monitoring from space.," in International Conference on Space Optics - ICSO 2018 (Vol. 11180, p1118021). International Society for Optics and Photonics.

[4] S. Gousset, E. Le Coarer, N. Guérineau, L. Croizé, T. Laveille and Y. Ferrec, "NANOCARB-21: a miniature Fourier-transform spectro-imaging concept for a daily monitoring of greenhouse gas concentration on the Earth surface," in International Conference on Space Optics - ICSO 2016 (Vol. 10562, p. 105624U). International Society for Optics and Photonics.

[5] S. Gousset, L. Croizé, E. Le Coarer, Y. Ferrec and L. Brooker, "NanoCarb part 2: Performance assessment for total column CO2 monitoring from a nano-satellite.," in International Conference on Space Optics-ICSO 2018 (Vol. 11180, p. 111803Q). International Society for Optics and Photonics. .

[6] J. M. Smit, J. H. Rietjens, G. van Harten, A. Di Noia, W. Laauwen, B. E. Rheingans and O. P. ... \& Hasekamp, "SPEX airborne spectropolarimeter calibration and performance," Applied optics, vol. 58(21), pp. 5695-5719, 2019.

[7] T. Krings, K. Gerilowski, M. Buchwitz, M. Reuter, A. Tretner, J. Erzinger, D. Heinze, U. Pflüger, J. P. Burrows and H. Bovensmann, "MAMAP - a new spectrometer system for column-averaged methane and carbon dioxide observations from aircraft: retrieval algorithm and first inversions for point source emission rates," Atmospheric Measurement Techniques, no. 4, pp. 1735-1758, 2011.

[8] S. Gousset, L. Croize, E. Le Coarer, Y. Ferrec, J. Rodrigo-Rodrigo and L. Brooker, "NanoCarb hyperspectral sensor: on performance optimization and analysis for greenhouse gas monitoring from a constellation of small satellites," CEAS Space Journal, vol. 11(4), pp. 507-524, 2019.

[9] A. Delannoy, B. Fièque, P. Chorier and C. Riuné, "NGP: a new large format infrared detector for observation, hyperspectral and spectroscopic space missions in VISIR, SWIR and MWIR wavebands," in sensors, systems, and next-generation satellites XIX. Int. Soc. Opt. Photonics 9639, 96390R, 2015. 
[10] F. De la Barrière, Y. Ferrec, L. Croizé, H. Ehrhardt, S. Gousset and E. Le Coarer, "Instrumental development of NanoCarb, a new spectro-imaging sensor," in ICSO, 2021.

[11] B. J. Frey, D. B. Leviton and T. J. Madison, "Temperature-dependent refractive index of silicon and germanium," Optomechanical technologies for Astronomy, vol. 6273, p. 62732J, 2006, July. International Society for Optics and Photonics.

[12] A. Butz, O. P. Hasekamp, C. Frankenberg, J. Vidot and I. Aben, "CH4 Retrievals from Space-Based Solar Backscatter Measurements: Performance Evaluation against Simulated Aerosol and Cirrus Loaded Scenes,” Journal of Geophysical Research, vol. nº D24, no. Atmospheres 115, 2010. 